HEALTHCARE DELIVERY

\title{
Rural district hospitals - essential cogs in the district health system - and primary healthcare re-engineering
}

\begin{abstract}
K W D P le Roux, I Couper
Karl le Roux is based at Zithulele Hospital, Eastern Cape, South Africa. He is an honorary lecturer in the Primary Health Care Directorate, Faculty of Health Sciences, University of Cape Town, and a member of the Rural Doctors Association of South Africa Executive Committee. Ian Couper, a family physician by training, is Professor of Rural Health at the University of the Witwatersrand, Johannesburg, South Africa. He is Director of the Wits Centre for Rural Health, which was launched in 2009 with a focus on human resources for rural health, and holds a joint appointment in the North West Provincial Department of Health as Head: Clinical Unit (Rural Medicine). His areas of interest are health service development, undergraduate and postgraduate education, research and advocacy.
\end{abstract}

Corresponding author: Kle Roux (karlleroux@gmail.com)

The re-engineering of primary healthcare (PHC) is regarded as an essential precursor to the implementation of National Health Insurance in South Africa, but improvements in the provision of PHC services have been patchy. The authors contend that the role of wellfunctioning rural district hospitals as a hub from which PHC services can be most efficiently managed has been underestimated, and that the management of district hospitals and PHC clinics need to be co-located at the level of the rural district hospital, to allow for proper integration of care and effective healthcare provision.

S Afr Med J 2015;105(6):440-441. DOI:10.7196/SAMJ.9284

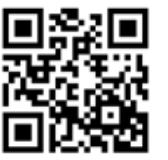

The South African National Department of Health $(\mathrm{NDoH})$ has in the past few years committed to re-engineer and improve primary healthcare (PHC) as an essential precursor to the planned implementation of National Health Insurance (NHI). The Minister of Health, Dr Aaron Motsoaledi, has repeatedly emphasised that the foundation of NHI will be proper PHC, with a focus on prevention and health promotion. ${ }^{[1,2]}$ Unfortunately, improvements in PHC have been slow in coming and the gains made have been patchy at best. ${ }^{[3]}$ There continues to be a gap between policy and implementation, especially in rural districts, that needs to be addressed.

We contend that an important reason why the re-engineering of PHC has made so little impact is that the role of the well-functioning district hospital as an essential part of the delivery of PHC services has been ignored. Furthermore, the physical separation of the management of district hospitals and that of PHC clinics in health districts has caused fragmentation and poor integration of care between clinics and hospitals, and has perpetuated a curative instead of preventive mindset at district hospitals - contrary to the PHC approach.

Unless district hospitals are strengthened and enabled to function as an essential part of the district health system (DHS), and are seen to be part of the implementation of the PHC approach, the laudable aim of re-engineering PHC in South Africa (SA) is likely to fail. This will be further facilitated if management of (sub-)district health services and district hospitals are co-located.

\section{Background - weakness of PHC delivery in SA and plans to improve this}

Over the past 20 years, the SA PHC system has undergone a process of significant realignment and change. The philosophy of PHC has been set down as the foundation principle on which the public health system is to be built, in line with the ideals of the 1979 AlmaAta Conference and clear evidence of the effectiveness of the PHC approach. ${ }^{[4]}$
The DHS is the vehicle that the $\mathrm{NDoH}$ has used in its attempt to provide comprehensive PHC to all SA citizens. This has required significant restructuring of systems, including the redrawing of district boundaries to fit in with municipal boundaries, provincialisation of healthcare facilities, reorganisation of referral pathways and appointment of district management teams. Hundreds of new clinics have been built, nurses have been trained as PHC practitioners, community health workers have been sent into people's homes, and the SA immunisation schedule has been expanded to the envy of most developing countries.

Yet, by the NDoH's own admission, 'insufficient attention has been given to the implementation of the PHC approach that includes taking comprehensive services to communities, emphasising disease prevention, health promotion and community participation. ${ }^{[5]}$ This is illustrated by poor outcomes in critical areas such as maternal and under-5 mortality rates, despite the relatively high expenditure on health in SA. ${ }^{[6]}$ While acknowledging that the HIV epidemic has had a devastating impact, it is clear that good-quality, comprehensive and integrated PHC has remained an elusive goal, which has led the $\mathrm{NDoH}$ to refocus on PHC in the past few years.

After a visit to Brazil by several senior members of the $\mathrm{NDoH}$ in 2010, discussion documents were compiled outlining the Department's plan to re-engineer PHC. ${ }^{[5,7]}$ This plan hinges on community-based care through ward-based outreach teams, more effective use of community health workers, leadership, support and planning by district clinical specialist teams (DCSTs), and improving school health services.

Unfortunately, despite much initial optimism from civil society and government role players, the implementation of a re-engineered PHC has faced significant challenges and appears to have made little impact (T Padayachee et al., 'The status of the implementation of primary health care re-engineering' (Health Systems Trust, 2014) poster presentation at the Public Health Association of South Africa Conference 2014, accessed via personal communication). The goal of good-quality, comprehensive PHC services remains elusive. 


\section{Two major areas that need to be addressed}

There are several reasons why the re-engineering of PHC has been disappointing, including the fact that hardly any extra resources were committed to the initiative, apart from budgeting for the DCSTs. Two of the most important reasons relate to the essential place of the district hospital within the DHS, especially in underserved rural areas.

Firstly, as documents outlining the re-engineering process confirm, the critical role that well-functioning district hospitals can play in the delivery of PHC services was unfortunately completely overlooked. ${ }^{[5,7]}$ This apparent oversight may reflect the fact that, historically, the hospicentric approach to care has been a major impediment to the implementation of the PHC approach. However, it is clear from World Health Organization, Health Systems Trust and even $\mathrm{NDoH}$ documents that the role of the district hospital as the vehicle for implementing the PHC approach is an extremely important one. ${ }^{[8-11]}$ In our opinion, high-quality, comprehensive PHC services will only be achieved if the district hospitals are central to the planning, integration and delivery of PHC services, and are seen as key implementing vehicles for $\mathrm{PHC}$ revitalisation, especially in rural areas.

The advantages of well-run district hospitals are significant, as they are able to attract and retain a core community of skilled healthcare workers (unlike community health centres, where the core is too small), act as a hub from which PHC services can be supported and organised, and serve as a vital link in the referral chain. District hospitals are also very cost-effective if measured by cost per disability-adjusted life year gained, both for inpatient care and essential surgical care such as caesarean sections. ${ }^{[9,12]}$

There are several rural hospitals (such as Mseleni and Bethesda in northern KwaZulu-Natal Province and Zithulele in the Eastern Cape) with a core of long-term clinical staff that have made outreach to clinics a priority; ${ }^{[13]}$ as a result, PHC services have been greatly improved in the areas served by these hospitals. Regular outreach has supported clinic nurses, improved quality of clinical care and patient satisfaction, and been essential to down-referral of patents on antiretovital therapy.

Secondly, and related to what has been set out above, in most health subdistricts the management and organisation of PHC clinics has been completely separated from that of district hospitals. This has led to fragmentation and a vertical, silo-type approach to the different programmatic aspects of PHC. As a result, district hospitals stand alone and disconnected from PHC services in a district or subdistrict and from the clinics that refer to them. This is partly responsible for the curative mindset that continues to bedevil the approach to healthcare delivery, rather than the community-orientated approach with a focus on illness prevention and health promotion that is so desperately needed.

The situation has been described as follows: 'having separate management structures for your hospital and for clinics would be like a human body having one brain that controlled your legs and another brain that controlled your arms - it could work, but it would never be as good as one brain coordinating all limbs. ${ }^{[14]}$ The way in which healthcare services in districts have been organised does not make practical sense, and is also, according to the Disease Control Priorities Project, economically wasteful because the failure to recognise the interrelationship between local- and district-level facilities has resulted in inefficiency and high costs in service provision. ${ }^{[9]}$

The need for the establishment of amalgamated primary care management teams (PCMTs) cannot be over-emphasised. Based at the district hospital, PCMTs would oversee clinic and district hospital care as an integrated whole, and mitigate the disconnect that currently exists between district and subdistrict management teams and clinicians (nurses, doctors and therapists).

If the $\mathrm{NDoH}$ seeks to improve $\mathrm{PHC}$, district hospitals need to be strengthened and fully integrated into the DHS. The PHC approach needs to be integral to thinking at all levels in the DHS with clinical managers, doctors and therapists at district hospitals having a clear understanding that they are responsible for the health of all individuals in their hospital's catchment area, and not just patients who walk through the hospital gate. This will reduce the centralisation of resources, preventing district hospitals from absorbing too much time and attention, and allow for continuity of care within the context of a team working across the (sub-)district.

Feedback and communication between district hospitals and clinics need to be strengthened in both directions, and skills and resources at district hospitals must be mobilised to improve clinic and community care. Clinic outreach, use of standard clinical protocols, planning and training emanating from district hospitals all need to be co-ordinated by PCMTs, with support from the DCSTs, and clinicians should be strongly supported in their mission to provide care for the greater community.

\section{Conclusion}

The current modus operandi of separating the management of clinics and district hospitals within the DHS is often dysfunctional (particularly in the rural areas) and undermines effective provision of PHC in a (sub-)district. 'Re-engineering of PHC' will continue to be ineffectual unless the critical role of the district hospital in the delivery of good-quality PHC services is recognised. Not only should the district hospital be the site where PCMTs are based, it should also serve as a hub of expertise, training, supervision and support for its feeder clinics and be the guardian of the health of each member of community it serves. The well-functioning district hospital, in the context of the integrated DHS, should be the cornerstone of attempts to build a strong and comprehensive PHC system and a healthier SA.

1. Business Day Live. Primary healthcare will be heartbeat of NHI, says health minister. http://www. bdlive.co.za/national/health/2013/10/16/primary-healthcare-will-be-heartbeat-of-nhi-says-healthminister (accessed 13 October 2014).

2. Minister Aaron Motsoaledi: Health Department Budget Vote 2013/14. http://www.gov.za/speeches view.php?sid=36484 (accessed 13 October 2104$)$.

Business News, IOL. Mountain to climb in primary health care. http://www.iol.co.za/business/news/ mountain-to-climb-in-primary-health-care-1.1584301\#.VDw1HOfq3gx (accessed 13 October 2104)

4. Rohde J, Cousens S, Chopra M, et al. 30 years after Alma-Ata: Has primary health care worked in countries? Lancet 2008;372(9642):950-961. [http://dx.doi.org/10.1016/S0140-6736(08)61405-1]

Barron P, Shasha W, Schneider H, et al. Re-engineering Primary Health Care in South Africa. Department of Health, Pretoria. Discussion document. 2010. www.anovahealth co za/images/upload PHC_rengineering_narrative_24_Nov_Final.dot (accessed 4 May 2015).

6. Chopra M Daviaud E. Pattinson R, Fonn S. Lawn JE. Saving the lives of South Africa's mothers, Chopra M, Daviaud E, Pattinson R, Fonn S, Lawn JE. Saving the lives of South Africas mothers babies, and children: Can the health system deliver? Lancet 2009;374(9692):835-846. [http://dx.doi.

Pilly Y Barron P. The implementation of PHC re-engineering in South Africa. Public Health Association of South Africa, 2011. http://www.phasa.org.za/the-implementation-of-phc-reengineering-in-south-africa/ (accessed 20 October 2104).

8. Department of Health, Pretoria. A district hospital service package for South Africa - a set of norm and standards. 2002. www.kznhealth.gov.za/norms.pdf (accessed 4 May 2015).

9. English M, Lanata CF, Ngugi I, Smith PC. The district hospital. In: Jamison DT, Breman JG, Measham AR, et al., eds. Disease Control Priorities in Developing Countries. 2nd ed. Washington, DC: World Bank, 2006. http://www.ncbi.nlm.nih.gov/books/NBK11749/ (accessed 13 October 2014).

10. McCoy D. The role of the district office in the DHS. Health Systems Trust, 1998. http://www.hst.org.za/ publications/role-district-office-dhs (accessed 20 October 2014)

1. Van Lerberghe W, Lafort $\mathrm{Y}$. The role of the hospital in the district: Delivering or supporting primary health care? World Health Organization, 1990. http://apps.who.int//iris/handle/10665/59744 (accessed 20 October 2014).

12. McCord C, Chowdhury Q. A cost effective small hospital in Bangladesh: What it can mean for emergency obstetric care. Int J Gynecol Obstet 2003;81(1):83-92. [http://dx.doi.org/10.1016/S00207292(03)00072-9]

13. RuDASA, RHAP. The district hospital and PHC. http://www.rhap.org.za/the-district-hospital-and$\mathrm{phc} /$ (accessed 20 October 2014).

14. McCoy D. District hospitals. Health Systems Trust, 1998. http://www.hst.org.za/publications/districthospitals (accessed 20 October 2014) 